\title{
Treatment of Multiple Recessions with Minimally Invasive Technique: A Case Report
}

\author{
Dr. Ameena Pradhan \\ Assisstant Professor, Department of Periodontology and Oral Implantology, \\ People's Dental College, Kathmandu, Nepal
}

\begin{abstract}
Recession of the gingival margin remains a highly prevalent problem for its impact on both aesthetics and periodontal health. The search for a perfect root coverage technique has led to the development of a number of innovative surgical procedures to achieve consistently better and more predictable results. This case report introduces a simple minimal invasive surgical method "Modified Semilunar Coronally Advanced Flap Technique" to treat gingival recession in multiple teeth. This technique has shown additional advantage of minimal surgical site with no shortening of vestibule, better coronal mobility and stability of repositioned flap.
\end{abstract}

Key Words: Gingival recession, root coverage, modified semilunar coronally advanced flap, semilunar incision, dental esthetics

\section{INTRODUCTION}

Gingival Recession by definition is the location of marginal tissues apical to the cementoenamel junction. ${ }^{1}$ This condition may be associated with periodontal disease or related to mechanical factors such as faulty tooth brushing. Patients with gingival recession seek treatment because of esthetic appearance of the dentition and/or root sensitivity. However, it also leads to plaque accumulation resulting in further attachment loss, root caries and difficulty in oral hygiene maintenance. Because of these functional and esthetic anomalies, obtaining predictable and esthetic root coverage has become an important goal for a periodontal plastic surgeon.

In the last few decades several surgical techniques have been proposed to treat gingival recessions, like minimal invasive semilunar flap (Tarnow 1986) ${ }^{2}$ to more invasive technique like the free gingival graft (Sullivan \& Atkins 1968)' the coronally advanced flap (CAF, Allen \& Miller 1989)4, the CAF with a subepithelial or connective tissue graft (Langer \& Langer 1985$)^{5}$, and various regenerative procedures such as the use of non-resorbable barriers (Pini Prato et al. 1992) ${ }^{6}$, bio-resorbable barriers, enamel matrix derivative, or the application of a platelet-rich gel in combination with CAF. Although all these techniques have shown a consistent potential for root coverage, meta-analyses from several systematic reviews reveal an ample degree of variability of clinical results.

\footnotetext{
Correspondence:

Dr. Ameena Pradhan

Department of Periodontology \& Oral Implantology,

People's Dental College, Kathmandu, Nepal

email: docameenapradhan@gmail.com

\section{Citation}

Pradhan A. Treatment of multiple recessions with minimally invasive technique: a case report. J Nep Soc Perio Oral Implantol. 2017;1:32-3.
}

Among these various techniques, Modified semilunar CAF technique for multiple teeth recession given by Kamaran Haghighat in $2006^{7}$ has additional advantage of minimal surgical site with no vestibule shortening, better coronal mobility and stability of the repositioned flap.

\section{CASE REPORT}

A 23 year-old female patient reported to the Department of Periodontics with complaint of sensitivity and long appearing upper front teeth. She was systemically healthy and non smoker.

On examination, recession defects were present on 11 and 12. The patient showed good plaque control and tissues showed no signs of inflammation. The biotype was visually determined to be thick with an adequate band of keratinized gingiva. Depth of buccal vestibule was also found to be adequate. A thorough plaque control programme and correction of faulty tooth brushing habit was initiated. Gingival recession closest to the William's periodontal probe marking was measured. The area of operation was anesthetized using Lignocaine 2\% with adrenaline 1:200000. Using Bard Parker no. 15 Blade, a semilunar incision was made apically, following the curvature of the gingival margin of the teeth exhibiting gingival recession. The most apical extent of the arc of this incision was typically located in the mucosa. The lateral extensions of incisions curved coronally within the keratinized tissue to terminate apical to the papilla, mesial and distal to the teeth exhibiting recession such that the vascularity to the mobilized pedicle was not compromised. A partial thickness sulcular incision was made along the gingival margins of the two adjacent teeth which extended to create a new papilla tip located apical to the original papilla, at a distance equal to that of the recession defect. Then the remaining original papilla was de-epithelialized and the partial thickness flap was coronally advanced, with newly created papilla positioned over the de-epithelialized segment. The flap was sutured through the 


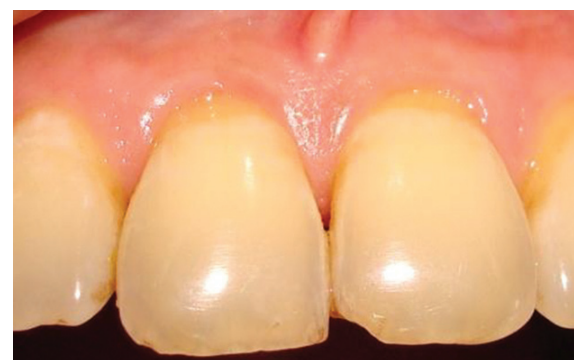

Figure 1: Preoperative

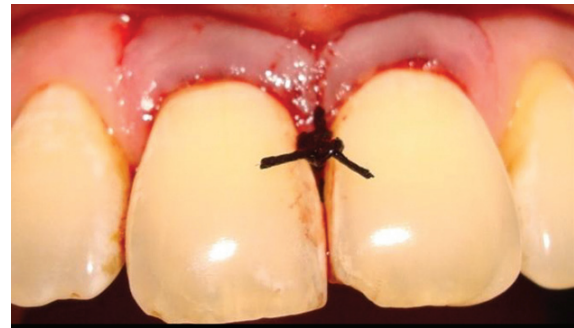

Figure 3: Coronally positioned and sutured

middle papilla to stabilize it coronally and held in place with moist gauze against the tooth surface for 5 minutes. The area was covered with a periodontal dressing and post surgical instructions were given. Patient was instructed to rinse with Chlorhexidine gluconate $0.2 \%$ for 1 minute twice daily for two weeks and an analgesic (Ibuprofen 400mg 8 hourly) was prescribed for 3 days. Sutures were removed after a week. The postoperative healing after 3 months revealed satisfactory results.

\section{DISCUSSION}

The success of root coverage procedure is determined by the amount of recession covered as assessed by measuring the distance between the cementoenamel junction and the gingival margin. Absence of bleeding on probing, reduce hypersensitivity, colour matching with adjacent tissue and no clinical attachment loss are additional criteria for successful root coverage. The predictability of coverage of the exposed root surface is influenced by many factors like appropriate case selection with no loss of interdental papilla and interdental alveolar bone adjacent to gingival recession, sufficient blood supply ensured to donor tissue, root surface covered with thick donor tissue (flap and graft), donor tissue adapted closely to the recipient site, and sutured. ${ }^{8}$ Along with these factors selection of appropriate surgical technique also affect the success rate of root coverage. Key factors

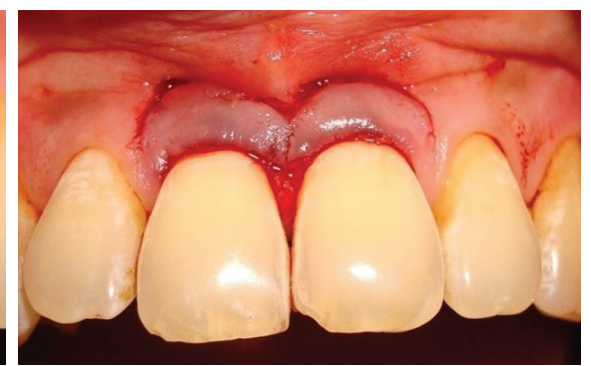

Figure 2: Partial thickness flap with new papilla

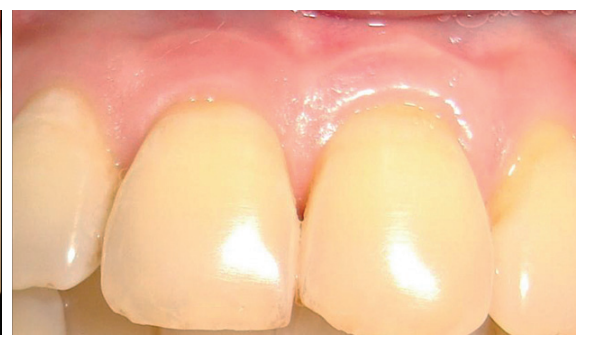

Figure 4: Post-operative 3months

while selecting surgical procedure are degree of gingival recession, whether gingival recession is limited to single or multiple teeth, amount and thickness of keratinized gingiva in the area of recession, relation between height of adjacent interdental papilla and gingival recession. ${ }^{8}$

As in this case gingival recession was present in multiple teeth and there was adequate amount of attached gingiva and vestibular depth so minimal invasive surgical technique, Modified semilunar coronally positioned flap, was chosen, new interdental papilla was created and sutured so that better stability of coronally advanced flap is secured (gained). This technique is useful in highly scalloped gingival margins where coronal manipulation and stability are difficult. To employ this technique, adequate thickness and width of keratinized tissue should be present apical to the defect. This particular incision design allows for partial thickness dissection over the middle papilla, which provides for adequate vascularity and better repositioning and it also eliminates potential scarring from vertical incisions.

\section{CONCLUSION}

The "Modified semilunar coronally advanced flap technique" used in the present study provides a satisfactory solution in the treatment of gingival recession in multiple teeth. Along with this, it also helps to gain the width of keratinized gingiva.

\section{REFERENCES}

1. American Academy of Periodontology. Glossary of periodontal terms. 4th ed. Chicago: American Academy of Periodontology; 2001.p.44.

2. Tarnow DP. Semilunar coronally repositioned flap. J Clin Periodontol. 1986;13:182-5.

3. Sullivan HC, Atkins JH. Free autogenous gingival grafts III. Utilization of grafts in the treatment of gingival recession. Periodontics. 1968;6:152-60.

4. Allen EP, Miller PD. Coronal positioning of existing gingiva: Short term results in the treatment of shallow marginal tissue recession. J Periodontol. 1989;60:316-9.

5. Langer B, Langer L. Subepithelial connective tissue graft technique for root coverage. J Periodontol. 1985;56:715-20.

6. Pini Prato G, Tinti C, Vincenzi G, Magnani C, Cortellini P, Clauser C. Guided tissue regeneration versus mucogingival surgery in the treatment of human buccal gingival recession. J Periodontol. 1992;63:919-28.

7. Haghighat K. Modified Semilunar coronally advanced flap. J Periodontol. 2006;77: 1274-9.

8. Sato N. Periodontal surgery. A clinical atlas. Illinois: Quintessence Publishing; 2000.p.336-421. 